\title{
Levels of Urine Cadmium in Children from Non-Polluted Areas of
}

\section{China}

\author{
Chengguang Zhao, ${ }^{1}$ and Yubin $\mathrm{Wu}^{1,{ }^{1}}$ \\ ${ }^{1}$ Department of Pediatric Nephrology, Rheumatology and Immunology, Shengjing Hospital of China Medical University, Shenyang, China \\ "Corresponding author: Yubin Wu, Sanhao street No 36, Heping District, Shenyang City, Liaoning province, China. E-mail: yubinwv@sina.com \\ Received 2016 June 24; Revised 2016 November 16; Accepted 2017 January 10.
}

\begin{abstract}
Objectives: The database on cadmium (Cd) concentration in children is limited, especially in China. The present study aimed at evaluating the body burden of $\mathrm{Cd}$ and to propose reference values for urine $\mathrm{Cd}$ in young children, who lived in areas with no point sources of metal exposure.

Methods: Overall, 1170 children aged from 1 month to 17 years old were enrolled in the study. A questionnaire was used to obtain essential information about age, gender, etc. Urine samples were collected to determine urinary Cd and urine creatinine.

Results: A total of 1070 children, 544 males and 526 females, were included in the analysis. Based upon their age, the population was divided to three age groups ( 0 to 5 years, 6 to 11 years, and 12 to 17 years). The reference value of urinary Cd for children without disease and Cd exposure was as follows: 0 to 5 years $<0.56 \mu \mathrm{g} / \mathrm{L}, 6$ to 11 years $<0.65 \mu \mathrm{g} / \mathrm{L}$, and 12 to 17 years $<0.74 \mu \mathrm{g} / \mathrm{L}$. The reference value of urinary Cd adjusted by urine specific gravity was as follows: 0 to 5 years $<0.83 \mu \mathrm{g} / \mathrm{L}, 6$ to 11 years $<0.01 \mu \mathrm{g} / \mathrm{L}$, and 12 to 17 years $<1.15 \mu \mathrm{g} / \mathrm{L}$. The reference value of urinary Cd corrected by urinary creatinine was as follows: 0 to 5 years $<2.17 \mu \mathrm{g} / \mathrm{L}, 6$ to 11 years $<1.23 \mu \mathrm{g} / \mathrm{L}$, and 12 to 17 years $<1.25 \mu \mathrm{g} / \mathrm{L}$.

Conclusions: In this study, we determined urine cadmium levels in children from non-polluted areas in china. The reference intervals could be used to offer recommendations for clinical work.
\end{abstract}

Keywords: Urine Cadmium, Children, Non-Polluted Areas, Urine Creatinine

\section{Background}

Cadmium (Cd) is a toxic heavy metal, which is prevalent in the environment (1). Since the beginning of the industrial revolution, Cd has been vastly released into the environment as a common byproduct in the processing of zinc and lead-containing ores (2). Long-term exposure, even at the lowest dose of cadmium, leads to many evidently adverse health effects in the organs, such as kidney, bone, lung, endocrine system, etc. (3). Animal models have shown the embryotoxic and teratogenic nature of Cd (4). Food, water, and air are the three sources of Cd pollution and air is majorly polluted by environmental tobacco smoking, house dust, and emissions from industrial activities (5). With a biological half-life of 10 to 30 years (6), Cd is excreted very slowly from the human body and cannot be metabolized easily (7). The primarily accumulated organs for Cd include kidneys and the liver (8). Therefore, even though current $\mathrm{Cd}$ emissions have been drastically reduced, Cd from early exposure or accumulation will continue to threat human health (9). However, no data reflecting the body burden of $\mathrm{Cd}$ in young Chinese mainland children was reported. In this study, we evaluated urine cadmium levels in Chinese children.

\section{Methods}

\subsection{Study Population}

A total of 1170 children aged from 1 month to 17 years old were enrolled in three districts, by a cluster random sampling method from five districts of Shenyang (China). The cases were from three communities: kindergartens, primary schools, and middle schools (except the senior year at high school). Socio-demographic data including age, gender, smoking habits, socioeconomic status, history of acute infection or chronic diseases were collected by questionnaires.

\subsection{Biochemical Assays}

Community doctors and teachers from kindergartens and schools were taught urine collection methods by specialists, who came from the pediatric nephrology department of Shengjing Hospital of China Medical University. Random spot urine specimens were collected in acidwashed bottles. Routine analyses of the urine samples were performed in the clinical laboratory of this university. Cadmium and creatinine in urine were measured. Urine Cd was determined by Graphite Furnace Atomic Absorption Spectrometry (GF-AAS, WS/T32-1996, Z5000, HITACHI, Japan). The detection limit was $0.28 \mathrm{ug} / \mathrm{L}$ for Cd in urine. 
If the level of urinary Cd was higher than $0.5 \mathrm{ug} / \mathrm{L}$, the average of three repeated measurements was recorded. Urinary creatinine was measured by an automatic biochemical analyzer (Biotek, USA) through an enzymatic method. To compensate for variation in urine dilution, the adjustments of the concentration of Cd were used. According to the correction formula, the concentration of $\mathrm{Cd}$ in urine adjusted by urine-specific gravity was calculated as follows: $(\mathrm{C})=$ the concentration of $\mathrm{Cd}$ in urine $(\mathrm{c}) \times \mathrm{k}, \mathrm{k}=1.020$ 1.000/(urine specific gravity-1.000).

\subsection{Statistical Analysis}

Statistical analysis was conducted by SPSS 16.0 software for windows. Observed cumulative probability to expected cumulative probability (P-P) and Kolmogorov-Smirnov test were used to examine the data distribution for normality. Mann-Whitney U-test or Kruskal Wallis test were used when univariate differences were compared between groups. The urine Cd level below the detection limit was uniformly calculated with half of the value of the limit of detection. When the proportion of values below the detection limit was more than 50\%, descriptive analysis was not used. Because $\mathrm{Cd}$ is harmful at high levels, right-sided 95\% confidence intervals were chosen as reference ranges. P values of less than 0.05 were considered significant.

\section{Results}

\subsection{General Information}

Initially, 1170 children were enrolled. Among them, 50 cases failed to complete the questionnaires or failed to collect their urine samples and were excluded from the study, including 25 smokers, 17 children with acute infection such as fever and pneumonia, 2 children with a history of liver disease, 3 with kidney disease, and 3 with diabetes. In total, 1070 cases, comprised of 544 males and 526 females, were included in the statistical analysis. The effective rate of the database was $96 \%$. Participants were divided to the following three age groups, 0 to 5 years, 6 to 11 years, and 12 to 17 years (Table 1 ).

Table 1. The Distribution of Age and Gender in Each Group

\begin{tabular}{lccc}
\hline Groups & Male & Female & Total \\
\hline 0-5 & $180(33.1)$ & $150(28.5)$ & 330 \\
$\mathbf{6}-\mathbf{1 1}$ & $180(33.1)$ & $150(28.5)$ & 330 \\
$\mathbf{1 2}-\mathbf{1 7}$ & $184(33.8)$ & $226(43.0)$ & 410 \\
Total & $544(100.0)$ & $526(100.0)$ & 1070 \\
\hline
\end{tabular}

${ }^{\mathrm{a}}$ Values are expressed as No. (\%).

\subsection{Population Reference Value}

The P-P plots showed that urine Cd did not satisfy the normal distribution in all age groups (Figure 1). The concentration of urinary Cd ranged from less than $0.28 \mu \mathrm{g} / \mathrm{L}$ to $1.77 \mu \mathrm{g} / \mathrm{L}$. The median was $0.31 \mu \mathrm{g} / \mathrm{L}$. There were no gender differences in urine $\mathrm{Cd}(\mathrm{P}>0.05)$. We also provided the corresponding reference intervals after adjustments. Reference ranges according to different ages for urine $\mathrm{Cd}$ with/without adjustment for creatinine and specific gravity are shown in Table 2.

\subsection{Compared with Hong Kong}

Compared with Hong Kong, the reference intervals of urine Cd in children of Shengyang was higher $(\mathrm{P}<0.05)$ (Table 3).

\section{Discussion}

It has been estimated that one cigarette probably contains 1 to $2 \mu \mathrm{g}$ of $\mathrm{Cd}$ (11) and Cd could be inhaled. In this present study, individuals who had never smoked were selected in the analysis to eliminate the effect of confounder smoking on the body burden (12). Therefore, the blood Cd concentrations reflect environmental exposure to $\mathrm{Cd}$ (13) and urinary $\mathrm{Cd}$ is a good biomarker of cumulative $\mathrm{Cd}$ exposure, and reflects life-time exposure, provided that the renal function is normal (14). After adjustment of urinary creatinine, the reference interval was $<2.17 \mu \mathrm{g} / \mathrm{gcr}$ in 0 to 5-year-old group and $<1.23 \mu \mathrm{g} /$ gcr in 6- to 11-year-old group. There was a higher reference value in the younger age group, which was in disagreement with the reference value of urine $\mathrm{Cd}$ with/without correction by urine specific gravity. The concentration of creatinine is highly dependent on body composition and type of diet (15). The present study had an age range from 1 month to 17 years, implicating a larger fluctuation of creatinine level. Thus, creatinine correction might interfere with the results, which were consistent with the idea supposed by Berlin et al. (16). Therefore, the observed values adjusted for specific gravity are more accurate than the commonly used creatinine adjustment (17).

In this study, the maximum concentration of urinary Cd was $1.77 \mu \mathrm{g} / \mathrm{L}$. Although there was no reported exposure of $\mathrm{Cd}$, contamination during the process of sample collection and measurement was also an issue that could not be ignored. Therefore, acid-washed bottles were used to collect samples in this study. If the level of urinary Cd was higher than $0.5 \mathrm{ug} / \mathrm{L}$, the average of three repeated measurements would be applied in the test. If there was a large fluctuation in the 3 detections, the lower value was used. 
A

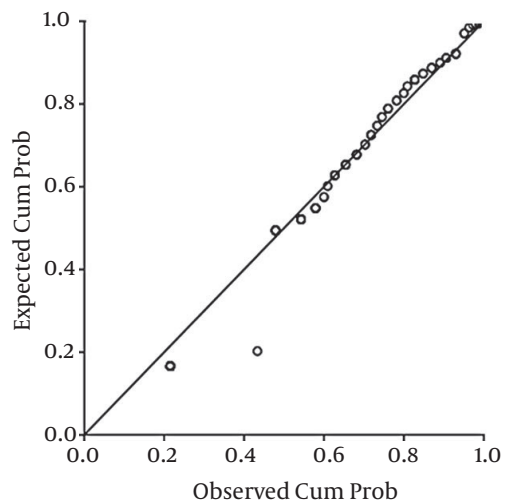

B

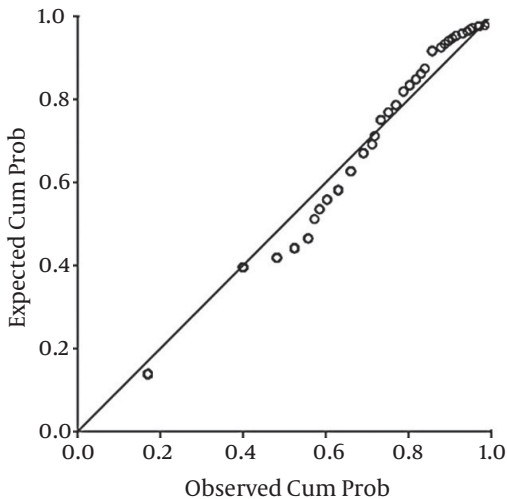

C

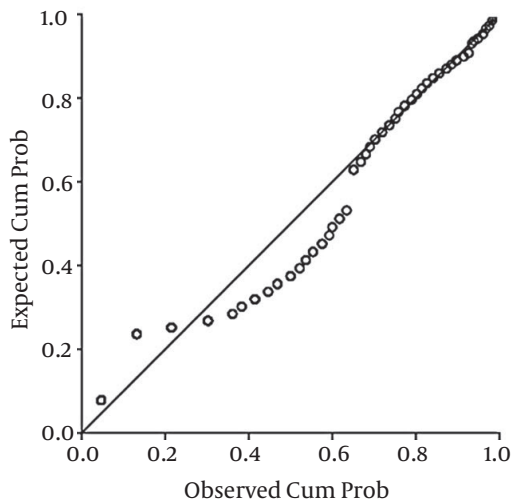

A, 0 to 5 years; $B, 6$ to 11 years; $C, 12$ to 17 years.

Table 2. Concentration of Cadmium in Urine Samples

\begin{tabular}{ccccc}
\hline Analysis & No. of Subjects & Urinary Cd, ug/L & Urinary Cd, ug/gcr & Urinary Cd, ug/L, Corrected by Specific Gravity \\
\hline 95\% reference interval, right-sided & & & & \\
0 - 5 years & 330 & 0.56 & 2.17 & 0.83 \\
6 - 11 years & 330 & 0.65 & 1.23 & 1.01 \\
12 - 17 years & 410 & 0.74 & 1.15 \\
\hline
\end{tabular}

Abbreviation: gcr, gram creatinine.

Table 3. The Comparison of Preference Values Between Shenyang and Hong Kong

\begin{tabular}{l|c|c|c}
\hline & Age Group, $y$ & No. of Subjects & $\begin{array}{c}\text { Cd Observed, } \\
\text { ug/L }\end{array}$ \\
\hline \multirow{3}{*}{ Present study } & $0-5$ & 330 & $0.56^{\mathrm{a}}$ \\
\cline { 2 - 4 } & $6-11$ & 330 & $0.65^{\mathrm{a}}$ \\
\cline { 2 - 4 } & $12-17$ & 410 & 0.75 \\
\hline \multirow{3}{*}{ Chan et al. (10) } & $1-5$ & 700 & 0.33 \\
\cline { 2 - 4 } & $6-10$ & 193 & 0.40 \\
\cline { 2 - 4 } & $11-15$ & 1136 & 0.75 \\
\hline
\end{tabular}

${ }^{\mathrm{a}} \mathrm{P}<0.05$ compared with Hong Kong.

Through these methods, contamination could be vastly reduced.

Cadmium is a long-time contaminant, which accumulates from early life to adulthood. It has been reported that maternal exposure to $\mathrm{Cd}$ negatively regulates birth weight, head, and chest circumference in females (18). One primary mechanism may be related to the elevated Cd concentration in the placenta, originating from increased ma- ternal exposure (19), as a result of which Cd concentration in umbilical cord blood was increased and transferred to the fetus (20). Insufficient zinc level in fetus can cause intrauterine growth retardation (21). Gallagher et al. (22) suggested that reduced serum ferritin on behalf of Fe deficiency was related to higher $\mathrm{Cd}$ both in urine and blood. The rate of $\mathrm{Cd}$ absorption is increased if the nutritional status of calcium, iron or zinc is low (23). Thereby, it is necessary to keep a balance of trace elements in children to diminish the absorption of $\mathrm{Cd}$.

Children seem to be at high risk of Cd exposure. In Cdpolluted areas, diet is the main source of $\mathrm{Cd}$ exposure in non-smoking populations (24). A report showed that in a Cd-polluted rice basin, the urinary $\mathrm{Cd}$ excretion decreased by $40 \%$ after soil replacement (25). Therefore, we can diminish the concentration of $\mathrm{Cd}$ in high-level areas by soilreplacement. Besides food, air-based exposure and being more prone to micronutrient deficiency, mouthing or accidently swallowing objects, such as inexpensive jewelry, may also contribute significantly to Cd exposure during childhood (26). Therefore, it is of particular importance to maintain good healthy habits in infants. 
One of the limitations of our study was the measurement method. The GF-AAS was used to measure the levels of urine Cd in this study. The accuracy of this method is lower when compared to inductively coupled plasma mass spectrometry (ICPMS) (27). This might be the main reason for the slightly high level of urinary Cd compared with other studies. Another limitation of the present study was the lack of blood Cd evidence to support the high levels of urinary Cd.

\subsection{Conclusions}

Although there were some limitations in this study, we reported the reference values of urine Cd in healthy Chinese children without $C d$ exposure. The reference values of urinary Cd were also adjusted by urine-specific gravity and by urinary creatinine. These data will provide significant implications for future clinical diagnosis of Cd toxicity.

\section{References}

1. Moulis JM, Thevenod F. New perspectives in cadmium toxicity: an introduction. Biometals. 2010;23(5):763-8. doi:10.1007/s10534-010-93656. [PubMed: 20632201].

2. Johri N, Jacquillet G, Unwin R. Heavy metal poisoning: the effects of cadmium on the kidney. Biometals. 2010;23(5):783-92. doi: 10.1007/s10534-010-9328-y. [PubMed: 20354761].

3. Satarug S, Garrett SH, Sens MA, Sens DA. Cadmium, environmental exposure, and health outcomes. Cien Saude Colet. 2011;16(5):2587-602. [PubMed: 21655733].

4. Thompson J, Bannigan J. Cadmium: toxic effects on the reproductive system and the embryo. Reprod Toxicol. 2008;25(3):304-15. doi: 10.1016/j.reprotox.2008.02.001. [PubMed: 18367374].

5. Schoeters G, Den Hond E, Zuurbier $M$, Naginiene $R$, van den Hazel P, Stilianakis N, et al. Cadmium and children: exposure and health effects. Acta Paediatr Suppl. 2006;95(453):50-4. doi: 10.1080/08035320600886232. [PubMed: 17000570].

6. Bernard A. Cadmium \& its adverse effects on human health. Indian J Med Res. 2008;128(4):557-64. [PubMed:19106447].

7. Prozialeck WC, Edwards JR. Early biomarkers of cadmium exposure and nephrotoxicity. Biometals. 2010;23(5):793-809. doi: 10.1007/s10534-010-9288-2. [PubMed: 20107869].

8. Jarup L. Cadmium overload and toxicity. Nephrol Dial Transplant. 2002;17 Suppl 2:35-9. [PubMed: 11904357].

9. Pennemans V, De Winter LM, Munters E, Nawrot TS, Van Kerkhove E, Rigo JM, et al. The association between urinary kidney injury molecule 1 and urinary cadmium in elderly during long-term, lowdose cadmium exposure: a pilot study. Environ Health. 2011;10:77. doi: 10.1186/1476-069X-10-77. [PubMed: 21888673].

10. Chan IH, Kong AP, Leung TF, Tsui TK, Cheung RC, Osaki R, et al. Cadmium and lead in Hong Kong school children. Pathology. 2012;44(7):626-31. doi: 10.1097/PAT.0b013e328359cfe7. [PubMed: 23111475].

11. Jarup L, Akesson A. Current status of cadmium as an environmental health problem. Toxicol Appl Pharmacol. 2009;238(3):201-8. doi: 10.1016/j.taap.2009.04.020. [PubMed:19409405].

12. Satarug S, Moore MR. Adverse health effects of chronic exposure to low-level cadmium in foodstuffs and cigarette smoke. Environ Health Perspect. 2004;112(10):1099-103. [PubMed: 15238284].
13. Batariova A, Spevackova V, Benes B, Cejchanova M, Smid J, Cerna M Blood and urine levels of $\mathrm{Pb}, \mathrm{Cd}$ and $\mathrm{Hg}$ in the general population of the Czech Republic and proposed reference values. Int J Hyg Environ Health. 2006;209(4):359-66. doi: 10.1016/j.ijheh.2006.02.005. [PubMed: 16740414].

14. Bernard A. Renal dysfunction induced by cadmium: biomarkers of critical effects. Biometals. 2004;17(5):519-23. [PubMed: 15688856].

15. Nermell B, Lindberg AL, Rahman M, Berglund M, Persson LA, El Arifeen S, et al. Urinary arsenic concentration adjustment factors and malnutrition. Environ Res. 2008;106(2):212-8. doi: 10.1016/j.envres.2007.08.005. [PubMed: 17900556].

16. Berlin A, Alessio L, Sesana G, Dell'Orto A, Ghezzi I. Problems concerning the usefulness of adjustment of urinary cadmium for creatinine and specific gravity. Int Arch Occup Environ Health. 1985;55(2):107-11. [PubMed: 3988354].

17. Berglund M, Lindberg AL, Rahman M, Yunus M, Grander M, Lonnerdal $\mathrm{B}$, et al. Gender and age differences in mixed metal exposure and urinary excretion. Environ Res. 2011;111(8):1271-9. doi 10.1016/j.envres.2011.09.002. [PubMed: 21962832].

18. Kippler M, Tofail F, Gardner R, Rahman A, Hamadani JD, Bottai M, et al. Maternal cadmium exposure during pregnancy and size at birth: a prospective cohort study. Environ Health Perspect. 2012;120(2):284-9. doi:10.1289/ehp.1103711. [PubMed: 21862444].

19. Osman K, Akesson A, Berglund M, Bremme K, Schutz A, Ask K, et al. Toxic and essential elements in placentas of Swedish women. Clin Biochem. 2000;33(2):131-8. [PubMed:10751591].

20. Kippler M, Hoque AM, Raqib R, Ohrvik H, Ekstrom EC, Vahter M. Accumulation of cadmium in human placenta interacts with the transport of micronutrients to the fetus. Toxicol Lett. 2010;192(2):162-8. doi: 10.1016/j.toxlet.2009.10.018. [PubMed: 19854248].

21. de Burbure C, Buchet JP, Bernard A, Leroyer A, Nisse C, Haguenoer JM, et al. Biomarkers of renal effects in children and adults with low environmental exposure to heavy metals. J Toxicol Environ Health A. 2003;66(9):783-98. doi:10.1080/15287390306384. [PubMed: 12746126]

22. Gallagher CM, Chen JJ, Kovach JS. The relationship between body iron stores and blood and urine cadmium concentrations in US never-smoking, non-pregnant women aged 20-49 years. Environ Res. 2011;111(5):702-7. doi: 10.1016/j.envres.2011.03.007. [PubMed: 21507392].

23. Nawrot TS, Staessen JA, Roels HA, Munters E, Cuypers A, Richart T, et al Cadmium exposure in the population: from health risks to strategies of prevention. Biometals. 2010;23(5):769-82. doi: 10.1007/s10534-0109343-z. [PubMed: 20517707].

24. Trzcinka-Ochocka M, Jakubowski M, Razniewska G, Halatek T, Gazewski A. The effects of environmental cadmium exposure on kidney function: the possible influence of age. Environ Res. 2004;95(2):143-50. doi: 10.1016/j.envres.2003.10.003. [PubMed: 15147919].

25. Kobayashi E, Suwazono Y, Honda R, Dochi M, Nishijo M, Kido T, et al. Changes in renal tubular and glomerular functions and biological Acid-base balance after soil replacement in Cd-polluted rice paddies calculated with a general linear mixed model. Biol Trace Elem Res. 2008;124(2):164-72. doi:10.1007/s12011-008-8125-8. [PubMed: 18575818].

26. Weidenhamer JD, Miller J, Guinn D, Pearson J. Bioavailability of cadmium in inexpensive jewelry. Environ Health Perspect. 2011;119(7):1029-33. doi:10.1289/ehp.1003011. [PubMed: 21377949].

27. Zhang ZW, Shimbo S, Ochi N, Eguchi M, Watanabe T, Moon CS, et al. Determination of lead and cadmium in food and blood by inductively coupled plasma mass spectrometry: a comparison with graphite furnace atomic absorption spectrometry. Sci Total Environ. 1997;205(23):179-87. [PubMed: 9372629]. 